\title{
O TRABALHO COM FONTES ORAIS - DESAFIOS E TRAJETÓRIAS
}

\author{
Paulo Eduardo da Silva \\ Centro Estadual de Educação Tecnológica Paula Souza - CEETEPS \\ pauloedu.hist@gmail.com
}

\begin{abstract}
RESUMO
O presente artigo discorre acerca das dificuldades do trabalho com memórias da Educação Profissional no Estado de São Paulo. A partir da experiência de implantação de um centro de memória na escola técnica José Rocha Mendes, é feita uma análise acerca dos problemas com a documentação disponível, as muitas lacunas existentes e de que forma o concurso da história oral pode ser de grande valia no sentido de mitigar as dificuldades geradas por tais lacunas. Posto o problema, o artigo procura discutir os caminhos encontrados para a pesquisa e o resgate do passado da instituição. Trabalhando com entrevistas de personalidades do passado da escola e com o apoio da documentação remanescente, tornou-se possível recuperar, pelo menos em parte, um passado mudo há cinquenta anos.
\end{abstract}

Palavras-chave: História Oral. Memória. Educação profissional.

\section{THE WORK WITH ORAL SOURCES - CHALLENGES AND TRAJECTORIES}

\begin{abstract}
This paper discusses the difficulties of working with the memories of Professional Education in the State of São Paulo. From the experience of implementation of a memory center at the technical school José Rocha Mendes, the problems with an available documentation are analyzed, as well as the existing gaps and how the oral history can be of great value to mitigate the difficulties generated by these gaps. Given the problem, the paper longs to discuss the paths to research and rescue the institution's memories. Working with interviews of personalities of the past and with the support of the remaining documents, became possible recover, at least in part, a past muted for fifty years.
\end{abstract}

Keywords: Oral History. Memory. Professional education.

\section{EL TRABAJO CON FUENTES ORALES - DESAFÍOS Y TRAJETORIAS}

\section{RESUMEN}

El presente artículo discurre acerca de las dificultades del trabajo con memorias de la Educación Profesional en el Estado de São Paulo. A partir de la experiencia de implantación de un centro de memoria en la escuela técnica José Rocha Mendes, se hace un análisis sobre los problemas con la documentación disponible, las muchas lagunas existentes y de qué forma el auxilio de la historia oral puede ser de gran valor para mitigar las dificultades generadas por tales lagunas. Planteado el problema, el artículo trata de discutir los caminos encontrados para la investigación y el rescate del pasado de la institución. Trabajando con entrevistas de personalidades del pasado de la escuela y con el apoyo de la documentación remanente, se hizo posible recuperar, al menos en parte, un pasado mudo hace cincuenta años.

Palabras clave: Historia Oral. Memoria. Educación profesional. 


\section{LE TRAVAIL AVEC DES SOURCES ORALES - DÉFIS ET TRAJECTOIRES}

\section{RÉSUMÉ}

Cet article vise à aborder certains aspects du travail avec la mémoire de Enseignement professionnel dans l'État de São Paulo. Sur la base de l'expérience de la mise en place d'un centre de mémoire à l'école technique José Rocha Mendes, nous avons fait une analyse des problèmes liés à la documentation disponible, des nombreuses lacunes existantes et à la manière comment l'histoire orale peut être très utile pour atténuer les difficultés créées par de telles lacunes. Compte tenu du problème, l'article cherche à discuter les moyens trouvés pour la recherche et le sauvetage du passé de l'institution. Par moyen des interviews de personnalités du passé de l'école et avec le soutien de la documentation restante, il est devenu possible de récupérer, au moins en partie, un passé silencieux depuis plus de cinquante ans.

Mots clés: Histoire Orale. Mémoire. Formation professionnelle.

\section{INTRODUÇÃO}

Em 2011 a convite da prof ${ }^{a}$. Dra. Maria Lucia Mendes de Carvalho apresentamos um artigo para o Simpósio Raízes, Retratos e Evolução em Cem anos da Educação Profissional Pública no Estado de São Paulo. A partir da apresentação deste trabalho e com o incentivo de Maria Lucia iniciamos algumas ações com o objetivo de implantar um centro de memória que funcionasse dentro da Escola Técnica José Rocha Mendes.

De início nos pareceu um desafio demasiado grande. A escola àquela altura estava prestes a completar 50 anos de existência e em todas essas décadas absolutamente nada havia sido feito no sentido de se preservar sua memória e trajetória. Teríamos de iniciar o trabalho literalmente "tateando no escuro". O pouco de memória que a escola carregava em si se resumia a umas anedotas que sempre circulavam nas conversas informais e o fato de sermos o resultado da divisão da Escola Profissional Masculina (hoje, Escola Técnica Getúlio Vargas). Este fato tornou-se muito emblemático para nós, pois a Escola Profissional foi a primeira escola profissional pública do estado de São Paulo e motivo principal das comemorações de 2011.

\section{INVESTIGAÇÕES PRELIMINARES}

Como primeiro passo para o início do resgate de nossas memórias, optamos por investigar nossa origem e quanto da herança da Escola Profissional havia sobrevivido em nossa escola. Nesse sentido, a primeira coisa que nos chamou a atenção, foi um interessantíssimo conjunto de esculturas em bronze que se espalhava por alguns corredores da Rocha Mendes e que, para minha surpresa, ninguém na escola sabia absolutamente nada a respeito. Exceto por

Rev. Iberoam. Patrim. Histórico-Educativo, Campinas (SP), v. 5, p. 1-10, e019006, 2019 
algumas datas, as esculturas pouco diziam a respeito de seu passado, mas mesmo assim, chamavam a atenção por sua antiguidade. Algumas delas também estavam prestes a completar cem anos de criação, o que nos remetia à época da fundação da Getúlio Vargas. Bingo! Tínhamos puxado o primeiro fio para estabelecer nossa herança centenária com as antigas escolas de artesania do início do século XX.

Esse primeiro passo foi importantíssimo para que pudéssemos estabelecer um primeiro vínculo com a escola geratriz de toda nossa tradição. De fato, a investigação em torno das esculturas rendeu muitos dividendos no sentido de estabelecer as "permanências" que se fixaram na Rocha Mendes oriundas daquele longínquo início de século XX. Tal investigação não apenas serviu como primeiro ponto de foco no estudo de nosso passado, assim como em anos posteriores voltando ao tema, pudemos estabelecer de que maneira diversas práticas escolares não só sobreviveram como se fixaram, sendo passadas por gerações de professores que se sucediam na escola.

Dado este primeiro passo, outras questões foram se colocando à medida que o trabalho de pesquisa se aprofundava e cada vez mais esbarrava em certas dificuldades. A principal e talvez a maior delas dissesse respeito às falhas na documentação disponível. Atribuímos tais falhas a dois fatores que atingiram a escola em décadas anteriores. Em primeiro lugar, uma grande enchente que destruiu boa parte da documentação, diversas memórias e objetos e, em segundo, a sistemática destruição de documentos com a chancela da legislação vigente à época.

A inundação de proporções bíblicas que atingiu duramente a escola destruiu e/ou inutilizou uma parte considerável da memória escolar incluindo aí álbuns fotográficos, pinturas, equipamentos científicos e demais objetos que muito poderiam revelar acerca do passado escolar. A queima sistemática da documentação tomada por "inútil” segundo os parâmetros estabelecidos por governos anteriores, também silenciou para sempre importantes massas documentais de maneira irreparável e irrecuperável.

Havia, portanto, a necessidade de se encontrar meios de prosseguir nas pesquisas "driblando" as lacunas na documentação e, ao mesmo tempo, recuperar esse passado que pouco a pouco ia se perdendo e deteriorando sem que nada fosse feito.

Diante dessas e outras dificuldades e seguindo a orientação da Prof. a Maria Lucia, decidimos adotar a história oral como método de investigação e registro deste passado que se perdia aceleradamente. $\mathrm{O}$ trabalho com história oral poderia, até certo ponto, mitigar as falhas e os silêncios em nossa documentação, possibilitando com isso, superar certas dificuldades e, num primeiro momento, "alinhavar" o trabalho realizado na documentação e começar a dar um 
sentido para aqueles objetos, fotos e papéis os mais diversos que começavam a chegar às nossas mãos. Corrobora com este ponto de vista José Carlos Meihy:

\begin{abstract}
Ainda que muitas vezes a produção de entrevistas seja usada como alternativa para preencher vazios de documentos convencionais ou de lacunas de informações e até para complementar outros documentos, é importante ressaltar que se pode, de maneira positiva, assumi-la isoladamente e propor análises das narrativas para a verificação de aspectos não revelados, subjetivos, alternativos aos documentos escritos. Para uns é possível usar entrevistas quando não existem documentos - ainda que esse não seja o procedimento mais aceito. (MEIHY; HOLANDA, 2013, p. 24-25).
\end{abstract}

Passamos então a realizar um trabalho sistemático de entrevistas com personalidades que tiveram expressiva atuação no passado da escola, e na verdade, alguns deles ainda se mantêm atuantes na mesma instituição. O trabalho sistemático nos permitiu cobrir determinadas faltas e dar voz a certos períodos que, de outra forma, permaneceriam no silêncio e na obscuridade. Com este recurso nos foi possível abrir outros ramos de pesquisa, abordar temas e aspectos de nosso passado não contemplados pela frieza dos registros oficiais e "humanizar" uma parte de nossa história que a partir daí passou a ganhar substância e conteúdo.

Outro aspecto que veio a reforçar nossa escolha pela história oral, foi o fato de, como afirmou Meihy, "pode-se propor análises das narrativas para a verificação de aspectos não revelados, subjetivos, alternativos aos documentos escritos" (MEIHY; HOLANDA, 2013, p. 24) o que poderia abrir (e de fato abriu), um grande leque de possibilidades para o trabalho em um ambiente com grandes lacunas documentais. Foi comparando e analisando este material coletado em entrevistas que pudemos cobrir diversos aspectos da vida escolar, dialogar com personagens e em alguns casos, dirimir dúvidas não contempladas no material disponível nos arquivos.

À medida que o trabalho com história oral prosseguia, a montagem de um acervo para nosso centro de memória também avançava. Com efeito, as entrevistas iam apontando possibilidades, caminhos, alternativas para os empecilhos criados pela documentação (ou a falta dela). Também nos alertavam para a importância ou a historicidade de determinados objetos. O trabalho com as entrevistas passa a atuar, portanto, no sentido de recuperar e valorar os significados daquele acervo que começava a se esboçar, atrelando-o ao contexto histórico e pedagógico em que as peças haviam sido produzidas. Além disso, havia ainda na escola centenas de fotos em papel dispersas em diversos departamentos e milhares em suporte digital igualmente dispersas, além de equipamentos científicos, fotográficos, eletroeletrônicos, troféus e uma quantidade infinita de itens que, de fato, participaram ou ainda participavam das práticas pedagógicas da escola e que, portanto, mereciam ser preservados. 
Foi nesse momento que percebemos que o material produzido nas entrevistas aliado à documentação de que dispúnhamos, criavam uma base sobre a qual poderíamos iniciar uma pequena narrativa em torno da própria história da instituição. Em princípio, tal narrativa atuaria como uma espécie de fio condutor que pudesse nortear e amalgamar nosso trabalho e conferir um sentido à trajetória traçada pela Rocha Mendes nas cinco décadas pelas quais passou. A tarefa, então, era imensa e estávamos apenas engatinhando no sentido de unir documentos e objetos num todo coerente e coeso. Só a pesquisa e o conhecimento de nosso passado poderiam nos fornecer o viés necessário para "costurar" o arcabouço material com as memórias ainda muito dispersas naquele universo escolar.

Seguindo esse raciocínio, passamos a investir cada vez mais na ideia de entrevistar determinados personagens que, além de emblemáticos para a história da escola, pudessem ainda discorrer sobre os primeiros anos do nosso “Ginásio Industrial”. Dessa forma, poderíamos acompanhar o passo a passo da formação da escola, das primeiras dificuldades, as primeiras descobertas e conquistas de uma instituição que já no seu primeiro dia de funcionamento, (só viríamos a tomar plena consciência disso mais tarde) carregava dentro de si uma grande herança de uma grande escola do passado.

\section{ENTREVISTAS}

Para começar a efetivar o projeto de história oral, convidamos para nossa primeira entrevista a figura mais emblemática de que dispúnhamos: o professor Édson João Patané. Este personagem se mostrou um verdadeiro banco de dados sobre a escola e as diversas fases pelas quais a instituição passou. Patané ingressou na Rocha Mendes em 1968 com apenas dez anos de idade para cursar o Ginásio Industrial (o que chamaríamos hoje de fundamental 1). Logo de início, os depoimentos deste professor se mostraram uma verdadeira preciosidade. Por morar no mesmo bairro, Patané tem memória da escola, antes mesmo de começar a frequentá-la. Num de seus relatos, ele nos revelou que ao terminar o primário e conversar com o pai a respeito de qual escola ele seria matriculado, ambos, ele e o pai, acreditavam que a nova escola industrial era, na verdade, uma escola de japoneses. Isso devido à imensa quantidade de nisseis que a frequentavam.

Bastou essa pequena frase para que nossa curiosidade a respeito da composição étnica da escola daquela época entrasse na pauta das muitas investigações que pretendíamos desenvolver. Tempos mais tarde, tive o prazer de revelar ao professor Patané e a toda 
comunidade escolar que em algumas turmas daquele período, até dois terços dos alunos eram nisseis.

A história oral logo de início já se mostrava um caminho bastante profícuo no sentido de revelar possibilidades investigativas que por outras vias poderiam talvez não se mostrar tão evidentes.

Acreditamos que o trabalho com história oral possa "humanizar" os estudos em torno da educação profissional, à medida que relatos como estes nos aproximam de personagens e épocas que se mostram excessivamente diáfanas e distantes em estudos que não lançam mão de relatos testemunhais. Apenas citando novamente Meihy:

Gradativamente, substituía-se a exclusividade dos nomes importantes e mesclava-se um rol de histórias cotidianas, que falavam de realidades bem comezinhas. [...] Os efeitos e a aceitação coletiva dessas narrativas determinaram seu sucesso independentemente do registro oficial, fossem em arquivos ou cartórios. (MEIHY; HOLANDA, 2013, p. 102-103).

Cada vez mais o trabalho com entrevistas se mostrava muito promissor e já começava a possibilitar determinadas leituras do acervo que sem o socorro das falas dos personagens do período, poderiam permanecer para nós como uma grande incógnita. Uma pequena frase, um desvio no relato, a lembrança inesperada de um fato fortuito, podem servir de pista para se construir uma nova linha de investigação relacionando pessoas, fatos, objetos e até mesmo, determinadas práticas pedagógicas tanto do passado quanto presente.

Assim começamos a construir passo a passo o passado de nossa unidade. Vez por outra, logo após o relato de algum entrevistado ou mesmo uma conversa informal de corredor, recuperávamos algum objeto num laboratório, numa sala de pintura ou mesmo no descarte de materiais e o destinávamos ao acervo de nosso centro de memória. Os relatos atuavam como verdadeiros guias para a montagem de nosso acervo. Com eles era possível estabelecer os vínculos entre a arte, os cursos, personagens, lugares e toda uma infinidade de relações entre passado e presente, mudanças e permanências da instituição que, ao longo do tempo, foram se tornando muito mais claras para nós.

A própria arquitetura do prédio escolar passou a literalmente assumir novos contornos a partir das histórias contadas pelos entrevistados. Há décadas corria pela escola a ideia de que o edifício em que funcionávamos era na verdade uma antiga fábrica que teria sido reaproveitado pelo governo para instalar a nova unidade recém-criada. Essa história se mostrou uma verdadeira lenda urbana, pois com a documentação disponível e o auxílio de relatos de exalunos que testemunharam a construção do prédio, pudemos apurar que ali nunca funcionou a tal fábrica e que o edifício nasceu mesmo no intuito de abrigar nossa escola. 
Nesse aspecto foi particularmente interessante o relato de um desses personagens que podemos chamar "emblemáticos". O Sr. Sérgio Tamanaha pertenceu ao grupo de alunos que ingressou na Getúlio Vargas, mas que por força do decreto que dividiu a escola do Brás em três unidades, terminou estudando na Rocha Mendes. Ele era, portanto, membro do seleto grupo de alunos que literalmente inaugurou nossa escola.

Morador da Vila Prudente, o Sr. Sérgio durante a infância circulava pela várzea do Córrego da Mooca onde se localiza a Rocha Mendes e pôde testemunhar a construção do prédio. Seu relato corroborava com o que nos mostrava a documentação relativa ao assunto, inclusive datas e lugares. Também nos contou que naqueles tempos éramos vizinhos involuntários do campo do "Estrela", o time de várzea do bairro. Vez por outra, o Sr. Sérgio passava pelas obras de construção da nova escola para assistir a uma disputa entre o time da casa e algum adversário. Pouco tempo depois, o Sr. Sérgio viria a engrossar o grande coro de nisseis que representavam mais da metade dos alunos da Rocha Mendes naquela época.

Existem também alguns aspectos imateriais da Educação Profissional, que apenas o trabalho com entrevistas pode aferir. O simples ingresso em uma escola profissional poderia representar um verdadeiro divisor de águas no destino de certas famílias.

É o caso dos imigrantes japoneses que vieram para o Brasil principalmente para trabalhar nas colheitas de café no início do século XX. O desenvolvimento industrial de São Paulo terminou por atrair esses imigrantes e seus filhos para a vida na cidade. $O$ exigente espírito nipônico cobrava aos filhos a responsabilidade: estudar, formar, ser o melhor. Assim, nosso personagem Sérgio Tamanaha estudou, se profissionalizou e pode abandonar a pobreza e as dificuldades do meio rural por uma vida melhor na capital do estado. Segundo as palavras do próprio Sr. Sérgio - “entrar em uma escola profissional era como entrar na USP”.

O trabalho com entrevistas pode aprimorar nosso olhar sobre a documentação. Podemos organizar estatísticas, elaborar tabelas e analisar resultados acadêmicos. Mas poder aquilatar os significados e o impacto dessas "histórias comezinhas" sobre a vida de pessoas e famílias e o próprio destino de seus descendentes (a filha do Sr. Sérgio também foi aluna da Rocha Mendes), apenas a convicção de quem viveu a experiência pode atestar.

Outro exemplo que não poderemos encontrar na documentação acadêmica é a importância conferida ao estudante em determinadas épocas. Num relato que me caiu em mãos, um ex-aluno do curso de Mecânica de uma escola técnica relatava que, ainda estudante, arrumou emprego em uma pequena indústria. Os demais trabalhadores da empresa eram muito mais velhos e mais experientes que ele, então com 14 anos apenas. 
Os funcionários mais antigos usavam de sua experiência para fabricar determinadas peças nos tornos. O problema é que trabalhando apenas "na experiência", a fabricação de peças se tornava um exercício de erro e acerto.

Os mais velhos, então, vinham pedir orientações ao "garoto". Por ter estudado o profissionalizante, ao ser questionado acerca de como produzir determinada peça, o garoto sacava seu lápis e começava a fazer cálculos. Segundo seu próprio relato, nunca dava errado. Assim, todos na oficina, antes de iniciar o fabrico de qualquer nova peça, vinham consultar "o garoto" que apesar da pouca idade, passou a ser respeitado no ambiente de trabalho, inclusive pela chefia da oficina, dada a enorme economia de material que a empresa passou a fazer.

São uns poucos exemplos de como a história oral pode ampliar a nossa noção de determinadas épocas e vislumbrar com outros olhos a importância ou não de certos aspectos do cotidiano, da história de vida, dos meandros da Educação Profissional, ou outros ramos do saber histórico.

\section{CONCLUSÕES}

A história oral não se limita à curiosidade, ao anedótico ou saudosismo. Ela pode ser fonte de uma percepção diferenciada do cotidiano, da época e do objeto de estudo. No campo das práticas escolares, por exemplo, é na história oral que encontramos um rico material de pesquisa, que, devido às políticas de preservação já discutidas neste artigo, em geral, nos faltam na documentação convencional. Exemplo disso é o excelente relato do prof. Patané já citado anteriormente:

\footnotetext{
Eu me lembro muito bem que na aula de fundição, nós fundíamos... Tinha um molde de gesso, e esse molde era a estátua do Chopin, então você comprava cera de abelha e a cera de abelha tinha aquele cheiro gostoso né? E você fundia aquela estatueta e levava pra casa né? Mostrava pros pais, aquilo era uma coisa que atraia muito, você ter aquele produto nas mãos. Fundia cinzeiros, então realmente era uma coisa... que você chegava por exemplo: tornear um trofeuzinho no torno de madeira e levar pra casa e colocar aquilo no seu quarto ou na sala - "ó, isso aqui fui eu que fiz". Acho que isso era um atrativo muito bom pros alunos na época. (CARVALHO; RIBEIRO, 2014, p. 234).
}

Diversos desses relatos nos ajudam a recuperar certos aspectos perdidos da memória escolar. O orgulho do aluno que entrou numa escola de prestígio, a empolgação daquele que descobre uma nova técnica, uma habilidade oculta, aquele que sente a vitória chegar na forma de reconhecimento. A subjetividade é uma constante no trabalho com entrevistas, mas também o é em nossa vida, em nosso cotidiano. Novamente recorro às ideias de Meihy e Holanda: “Ao 
se materializar em documento escrito, porém, a história oral ganha objetividade de qualquer outro documento grafado ou de análise historiográfica, porém deve ser interpretada sob o crivo da subjetividade que a produziu" (MEIHY; HOLANDA, 2013, p. 26).

Os primeiros anos de funcionamento da Etec José Rocha Mendes foram, por assim dizer, obscuros. A partilha da Getúlio Vargas, a mudança do Brás, a instalação de equipamentos na Vila Prudente, realocação de mobiliário, cursos e alunos em um novo endereço. Toda uma nova situação difícil de imaginar hoje em dia e, sobretudo, uma memória que depois de cinco décadas estava quase que totalmente perdida para nossa comunidade escolar e que sobrevivia, ainda que esmaecida pelo tempo, para pouquíssimos sobreviventes.

Victor Cañedo nasceu em Oviedo na Espanha, é pequeno empresário do setor metalúrgico, ex-aluno da Rocha Mendes e numa entrevista ao nosso centro de memória, pôde nos relatar um pouco desses primeiros dias do funcionamento de uma escola literalmente virada pelo avesso, tendo de continuar ensinando os alunos ao mesmo tempo em que se reconstruía e se estabelecia.

Natural seria pensar toda essa situação como algo horrível, um verdadeiro caos beirando ao pesadelo. Bem ao contrário disso, o Sr. Victor nos mostra uma situação bastante positiva em seu relato sobre o período:

Mas lá, [na GV], na $1^{\mathrm{a}}$ e $2^{\mathrm{a}}$ série, [a gente] passava em todas as oficinas, e na $3^{\mathrm{a}}$ e $4^{\mathrm{a}}$
serie você definia um ramo. A gente tinha uma visão de oito profissões lá, e aqui
[Rocha Mendes] eu já perdi. Fiquei em quatro oficinas lá, e aqui fiz três anos de
mecânica. Foi até uma vantagem, porque no primeiro ano, ajudei a montar as
máquinas, então a gente pegou uma bagagem muito maior. E por exemplo: eu que
tinha mais ligação com o professor por ser um pouco maior, eu aprendi bastante aqui
em termos de mecânica, e em termos de elétrica. Também, as oficinas eram meio
misturadas, então saímos daqui com uma boa base. Não fomos prejudicados com a
mudança de lá pra cá.

Todos esses relatos que misturam histórias de vida, experiências as mais diversas, práticas escolares, memórias, cotidiano e muitas outras que deixaram de ser aqui relatadas dado os limites deste artigo, muito contribuíram no sentido de estabelecer os rumos tomados pela Rocha Mendes em seus 50 anos de existência. Sem o concurso da história oral, talvez nossa percepção de certos eventos fosse distorcida pelas lentes do tempo decorrido desde a fundação. Poderíamos apenas olhar os aspectos formais do trabalho escolar, aprovações, evasões, estatísticas e nos esquecer que o principal são as pessoas. Ou como se costuma dizer - Não enxergar a floresta por causa das árvores. 


\section{REFERÊNCIAS}

ENTREVISTA com o professor Edson João Patané - auditório Edem Della Bella em 18 de agosto de 2012.

ENTREVISTA com o engenheiro Victor Cañedo Rodriguez - biblioteca Benedito Garcia em 22 de setembro de 2012.

ENTREVISTA com o ex-aluno Sérgio Tamanaha - auditório Edem Della Bella em 23 de outubro de 2013.

MEIHY, José C. S.; HOLANDA, Fabíola. História Oral: como fazer, como pensar. 2. ed. São Paulo: Contexto, 2013.

CARVALHO, Maria L. M.; RIBEIRO, Suzana L. S. História Oral na Educação: memórias e identidades. CEETEPS, 2014.

Recebido em: 01 de setembro de 2018 Aceito em: 21 de dezembro de 2018 